\title{
DisUASIÓN Y CASTIGO DESDE UNA PERSPECTIVA LOCKEANA
}

\author{
Deterrence and Punishment from a Lockean Perspective
}

\section{NICOLÁS MALOBERTI}

Liberty Fund, Inc.

\section{RESUMEN}

Este artículo elabora una teoría disuasoria del castigo sobre premisas lockeanas. Siguiendo a autores como Warren Quinn y Daniel Farrell, se sostiene que la justificación del derecho a castigar debe ser construida sobre el reconocimiento de la importancia de un derecho a formular amenazas de retaliación. Contrariamente a esos autores, la articulación de ese reconocimiento se realiza dentro de una teoría lockeana de los derechos individuales. Esto nos permite apreciar de una manera más adecuada el rol específico de la disuasión en una concepción plausible del castigo, y así responder a ciertas objeciones que se han formulado recientemente, especialmente por David Boonin.

Palabras clave: Justificación del castigo, retaliación, disuasión, Locke.

\begin{abstract}
This article formulates a deterrence theory of punishment based on Lockean premises. Following authors such as Warren Quinn and Daniel Farrell, it is claimed that a justification for the right to punish must be built upon the recognition of the importance of a right to issue retaliatory threats. Contrary to those authors, however, the articulation of such recognition is made within a Lockean theory of individual rights. This allows us to appreciate the specific role deterrence has in a plausible conception of punishment, and thus address certain objections that have been formulated recently, especially by David Boonin.
\end{abstract}

Key words: Justification of punishment, retaliation, deterrence, Locke. 


\section{INTRODUCCIÓN}

En la discusión filosófica, las justificaciones del castigo que descasan en un reconocimiento moral de la importancia de la disuasión han sido tradicionalmente resistidas. Se ha creído que ese reconocimiento implica la legitimidad de usar a un individuo como objeto para enseñar una lección a otros y la posibilidad de castigar a inocentes si así se pudiera lograr el mismo resultado. Se ha sostenido que a aquello que tendemos a considerar como un hecho normativo fundamental, es decir, el hecho de que el agresor ha actuado de una manera incorrecta, se le asigna un rol contingente. La importancia radica en que los otros crean en la responsabilidad del agresor y no en que efectivamente él sea el responsable.

El elemento disuasivo del castigo adquiere una importancia fundamental en las teorías consecuencialistas en general, y en el utilitarismo en particular. Las justificaciones retribucionistas del castigo, por otro lado, tienden a basarse en la noción de merecimiento. El agresor, se sostiene, merece ser castigado independientemente de las consecuencias positivas que dicho castigo pueda generar. La adopción de un enfoque retribucionista evita la implicancia sobre la posibilidad de castigar personas inocentes que acecha a sus contrapartes consecuencialistas. El problema es que esta mayor coherencia con una fuerte intuición moral, como es la que rechaza la legitimidad de castigar a personas inocentes por un bien social, se suele conseguir a costa de abandonar el reconocimiento moral a la instrumentalidad del castigo. De acuerdo a Kant, el teórico paradigmático del enfoque retributivo, dicha instrumentalidad implica la manipulación de un ser humano para beneficiar al resto, y esto es inmoral incluso cuando aquel ser humano haya violado los derechos de personas inocentes. ${ }^{1}$ Como los críticos del retribucionismo continuamente señalan, esta forma de meritocracia extrema parece reducir al castigo a un acto de mera venganza, y así se desvanece el proyecto de ofrecer una justificación racional a una práctica que la demanda.

La apreciación crítica de las teorías disuasorias del castigo es acertada, pero solamente cuando es dirigida contra la particular justificación utilitarista del castigo, y contra cualquier enfoque consecuencialista que conciba a la práctica del castigo como orientada a maximizar una determinada concepción del bien impersonal. Sin embargo, dentro de una teoría del castigo, la valoración de la disuasión puede realizarse desde premisas no consecuencialistas. En este artículo presento los lineamentos generales de una justificación disuasoria, pero no consecuencialista, del castigo. Las premisas sobre las que se asienta esta justificación son lockeanas. Se asume que los individuos tienen ciertos derechos básicos originarios de propiedad tanto sobre sus cuerpos como sobre los objetos externos que han apropiado de acuerdo a principios relevantes. Desde esta perspectiva, también se asume que los individuos tienen ciertos derechos de segundo orden, a los que podemos llamar derechos de enforcement, que tienen por fin permitir a los individuos proteger sus derechos de propiedad mediante diversas acciones coactivas. Entre estos derechos 
se encuentra el derecho a amenazar con retaliación, el derecho a la defensa propia y el derecho a obtener restitución.

En general, estos anteriores derechos de segundo orden no se consideran problemáticos. Los críticos de la perspectiva lockeana, sin embargo, han tendido a rechazar la plausibilidad de incluir un derecho a castigar entre estos derechos individuales de enforcement. Este escepticismo contra la idea de un derecho privado a castigar parecería surgir desde una posición que asigna al castigo un rol eminentemente social. Este artículo presenta una concepción alternativa del castigo mediante la cual se lo concibe como teniendo un fin de protección individual que no es significativamente distinto al de aquellos otros derechos de enforcement que no se consideran problemáticos, como podría ser la defensa propia. $^{2}$

Warren Quinn y Daniel Farrell ya han presentado iluminadoras reflexiones en búsqueda de estas bases individualistas del derecho a castigar. ${ }^{3}$ En este artículo reconstruyo sus reflexiones en el marco de una teoría más general de los derechos individuales de naturaleza lockeana. No pretendo ofrecer una interpretación o reconstrucción de la teoría del castigo del mismo Locke. Pretendo formular una teoría del castigo sobre ciertas creencias normativas características de la tradición lockeana. En particular, el reconocimiento del valor fundamental de la soberanía individual y su articulación en términos de derechos de propiedad. Argumento que las mismas consideraciones que nos llevan a justificar la asignación de estos derechos de propiedad a los individuos, tanto sobre sus cuerpos como sobre objetos externos, nos deberían llevar a justificar la suerte de garantía material que los derechos de enforcement proveen. Y la capacidad de castigar, cuando es entendida como la capacidad de hacer efectivas nuestras amenazas de retaliación, es de fundamental importancia en proveer esa garantía.

Esta particular concepción del castigo es más congruente con las premisas individualistas de la tradición lockeana que la concepción del castigo que podemos encontrar en el mismo Locke, como así también en otros autores cercanos a esta tradición, como Grocio y Robert Nozick. Más allá de esta mayor coherencia con una tradición intelectual, esta concepción alternativa del castigo presenta una justificación más convincente en sí misma de por qué infligir algún tipo de daño a aquellas personas que hayan infligido un daño a otros es una práctica adecuada, y no meramente el producto de nuestros apetitos de venganza o un ejercicio de ingeniería social. La primera sección de este artículo presenta un esbozo de la teoría lockeana de los derechos individuales e introduce la distinción entre derechos de propiedad y derechos de enforcement. La segunda sección se centra en el derecho a castigar. Se argumenta que las mismas consideraciones que nos llevan a defender los derechos básicos de enforcement, junto con un principio plausible de justicia distributiva, nos deberían llevar a defender tal derecho. La tercera sección responde a

2 Es necesario aclarar que el propósito de este artículo no es cuestionar la legitimidad del monopolio estatal sobre el ejercicio del derecho a castigar. El propósito es proveer el esbozo de una justificación moral del castigo sobre la cual luego pudiese erigir la defensa de dicho monopolio, y también establecer las restricciones básicas que debería observar para su legitimidad.

3 Véanse, en particular, Quinn (1985) and Farrell (1990). 
las principales objeciones que David Boonin ha alzado contra este tipo de enfoque en su reciente libro The Problem of Punishment.

\section{DERECHOS DE PROPIEDAD Y DERECHOS DE ENFORCEMENT}

De acuerdo al liberalismo lockeano, los individuos tienen ciertos derechos básicos "naturales", es decir, originarios o no adquiridos. Estos derechos pueden ser entendidos como estableciendo áreas de libertad moral sobre determinados rangos de acción. Sobre esas áreas, el individuo es considerado soberano. La promoción de beneficios sociales o la promoción del bien prudencial o moral del mismo individuo no son considerados como consideraciones capaces, al menos en sí mismas, de justificar el desconocimiento de la voluntad individual. Debido a que virtualmente todas las acciones humanas involucran el uso de recursos físicos, se sostiene que dichos derechos básicos individuales son mejor entendidos en términos de derechos de propiedad. Dentro del enfoque lockeano se considera a los individuos como propietarios de sus cuerpos y de aquellos recursos externos que apropien de acuerdo a determinados principios. ${ }^{4}$

Así, el liberalismo lockeano puede caracterizarse por la fundamental importancia que asigna a la capacidad de los individuos de conducir sus propias vidas. En definitiva, es este compromiso valorativo el que sustenta la asignación de esas áreas de libertad o soberanía que otros deben respetar. Pero si esto es así, parecería natural concluir que también existen razones para proveer a esos individuos de alguna garantía material que efectivamente esas áreas se respeten. Las acciones que infringen los derechos de los otros no deberían poseer una inmunidad moral contra la inferencia. Si creemos en la importancia fundamental de esas áreas de soberanía individual, es natural pensar que esa falta de inmunidad debería incluir, en particular, la falta de inmunidad contra la inferencia mediante acciones coactivas.

Recientemente, Eric Mack ha defendido la separación teórica entre derechos de propiedad sobre uno mismo y derechos de propiedad sobre recursos externos. ${ }^{5}$ Pero también la separación teórica con otros derechos, tales como el derecho a no ser engañado, y el derecho a que se cumplan las promesas que voluntariamente otros nos hagan. Mack sostiene que todos estos anteriores derechos son meramente diferentes codificaciones o articulaciones del principio moral básico del liberalismo lockeano, que sostiene que las personas deberían ser libres de vivir sus propias vidas de acuerdo a sus propias elecciones. En su opinión, el reconocimiento de todos estos derechos es necesario, pues ninguno de ellos es individualmente suficiente para dar una expresión adecuada a este principio en todos los contextos de interacción humana. Aunque Mack no trata el caso específico de los derechos de enforcement, es evidente que el mismo razonamiento se aplica en este caso, incluso con mayor fuerza.

4 El desacuerdo sobre cuáles son esos principios de apropiación define la distinción entre los libertarios clásicos, tal como Murray Rothbard (1988) y Robert Nozick (1974), y los así llamados libertarios de izquierda, quienes sugieren que la apropiación de recursos externos debe tener en cuenta consideraciones igualitarias. Sobre el libertarianismo de izquierda, véase, por ejemplo, Vallentyne y Steiner (2002) and Otsuka (2003).

$5 \quad$ Mack (2010). 
Desde una perspectiva lockeana, entonces, se sostiene que de la misma manera en que los individuos deben poseer un control exclusivo sobre determinados recursos materiales, ellos deben también tener un control exclusivo sobre ciertas acciones coactivas que son necesarias para asegurar dicho control sobre los recursos materiales. Es decir, las acciones que están contempladas dentro de estos derechos de enforcement de un individuo pueden ser realizadas sin tener que contar con el acuerdo de los otros, y estos otros tienen un deber de no interferencia con respecto a dichas acciones. Si la capacidad de los individuos de conducir y vivir sus vidas no debe estar supeditada a las voluntades de los demás individuos, incluidos los funcionarios públicos, la existencia de una garantía efectiva contra las violaciones de los otros no debería ser igualmente contingente. En definitiva, los individuos deben ser entendidos como poseyendo tanto derechos naturales de propiedad como derechos naturales de enforcement. Esto quiere decir, meramente, que la fuerza normativa de esos derechos no es contingente de la aprobación o reconocimiento estatal por medio de la legislación. Al contrario, la legitimidad de esa legislación y del mismo Estado es contingente del reconocimiento y respecto de esos derechos morales básicos.

La demarcación entre derechos de propiedad y derechos de enforcement es teóricamente importante. Sin embargo, es necesario notar que existe un grupo de acciones que puede contemplarse bajo las dos categorías. Estas son acciones que disponen de los recursos externos de tal manera de incrementar los costos que otros deben afrontar en caso de que decidan infringir derechos ajenos. Ejemplos de este tipo de ejercicio incluyen el uso de puertas y candados, la construcción de murallas o la instalación de todo tipo de cercas. En general, tendemos a acordar que los individuos deberían ser capaces de organizar sus recursos de esta manera si es que así lo deseen, y si no imponen riesgos a personas inocentes que conducen sus vidas sin infringir los derechos de propiedad de los demás. Es significativo notar que ninguno de estos mecanismos hace imposible que otros individuos decidan violar los derechos que protegen. La importancia de estos mecanismos radica en que son capaces de incrementar el costo de realización de las acciones violatorias, y para que ese incremento del costo tenga un efecto disuasivo no es necesario que dicho costo supere los beneficios esperados en su totalidad. Es suficiente que ese incremento convierta a la violación de derechos en una acción menos rentable que otras alternativas.

Por derechos de enforcement, entonces, entenderé los derechos que, por así decirlo, no están incluidos en esta mera manipulación de los recursos externos. Por el momento podemos distinguir tres tipos de derechos de enforcement en función de si su ejercicio típico precede, acompaña, o sigue a la comisión de la ofensa.

El primer tipo de derecho de enforcement es el derecho a formular amenazas de retaliación. Este tipo de amenazas son condicionales de la violación de los derechos de propiedad de un individuo. La formulación de este tipo de amenazas precede así la comisión de la ofensa, debido a que es un mecanismo esencialmente preventivo. Los fundamentos éticos de este derecho no han sido explorados de una manera profunda en la literatura filosófica. Sin embargo, este derecho es de fundamental importancia para entender la ética del castigo. 
La plausibilidad del derecho a formular amenazas de retaliación es clara una vez que hemos reconocido que los individuos deberían ser libres de disponer de sus recursos externos de tal forma de crear un riesgo real de daño a aquellos que decidan violar sus derechos. Pues si los alambrados electrificados permiten desviar una menor cantidad de recursos productivos de los que requiere una pared sólida igualmente efectiva, la formulación de meras amenazas requiere una menor desviación de recursos incluso. Si se argumenta que los individuos deben ejercer un control exclusivo sobre sus cuerpos y recursos externos sobre la base que ese control les permite vivir sus propias vidas de una manera más adecuada, ellos ciertamente deberían ser capaces de economizar en los recursos que deben asignar para propósitos defensivos. Esta economización les permitirá contar con mayores recursos para usos productivos, que es lo que en definitiva importa. La deseabilidad de esta economización es especialmente clara cuando las amenazas de retaliación no disminuyen las áreas de legítima libertad de los otros. La formulación de dichas amenazas contras las acciones que violan los derechos individuales no interfiere contra ninguna acción que se considera moralmente inobjetable. Por el contrario, tienen como objeto exclusivo a aquellas acciones que se consideran violatorias de los derechos de otros.

El segundo tipo de derecho de enforcement, el ejercicio del cual acompaña a la ofensa, es el derecho a la defensa propia. El derecho a la defensa propia es el derecho a usar la fuerza como forma de repeler un acto de agresión. La plausibilidad de este derecho es raramente cuestionada. Pero se puede brindar una razón adicional para justificar este derecho al notar que sólo tiene sentido invertir en medidas de prevención hasta un punto tal en que un mayor incremento en gastos preventivos no produce un incremento similar en términos de seguridad. En otras palabras, existe un nivel de vulnerabilidad que no tiene sentido eliminar. Los beneficios de eliminarlo no compensarían los costos necesarios para hacerlo una vez que tomamos en cuanto el desvalor de la vulneración y la probabilidad de su ocurrencia. Este grado de vulnerabilidad racional nos permite advertir por qué un derecho de defensa propia es moralmente necesario. Los individuos deberían ser capaces de organizar sus vidas de una manera racional, sin tener que aceptar los costos impuestos por aquellos para quienes los arreglos de protección que tienen sentido invertir no son suficientemente costosos como para reducir suficientemente la rentabilidad de sus violaciones.

El tercer derecho de enforcement es el derecho a obtener restitución, el ejercicio del cual se supone que sigue a la realización de la ofensa. El derecho a obtener restitución incluye el derecho a ser compensado por todos los daños derivados de la ofensa. Como es el caso con los derechos de enforcement anteriores, este derecho es raramente cuestionado. Es natural que sea así. Si no se reconociese a los individuos este derecho, los individuos a los cuales los medios de protección de los demás no imponen costos suficientes de disuasión podrían adquirir y retener las posesiones de los otros. ¿Pero por qué se les daría esta oportunidad si había razones para asignar esas posesiones a otros individuos en primer lugar? Si tiene sentido negar a los individuos un derecho a obtener restitución, también tendría sentido asignar derechos de propiedad sobre la base de las capacidades predatorias de los individuos, y así eliminar el desperdicio involucrado en 
las transferencias coactivas que unos impondrán a otros. Pero una asignación basada en las capacidades predatorias de los individuos no es una característica de ninguna teoría plausible.

Parecería ser entonces poco controvertido que se debe reconocer a los individuos estos tres derechos básicos de enforcement. Si esto es así, también parecería ser poco controvertido que esta asignación no está supeditada a un reconocimiento por parte del Estado. De la misma manera que la justicia de una distribución dada de la propiedad no puede estar condicionada a la sanción estatal, tampoco puede estarlo el sistema de sanciones necesario para mantener esa distribución relativamente estable. En este sentido, estos derechos de enforcement se consideran tan "naturales" como los derechos de propiedad cuya función es hacer respetar. Nada de esto invalida necesariamente la legitimidad del monopolio estatal sobre la administración de aspectos importantes de esos derechos. Implica, meramente, que la legitimidad de ese monopolio debe juzgarse en función de la existencia previa de esos derechos. De acuerdo a una concepción lockeana, los individuos anteceden moralmente al Estado, y los derechos del Estado deben ser de alguna manera derivados de los derechos de los individuos, o por lo menos de la importancia que a ellos se reconoce.

\section{EL DERECHO A CASTIGAR}

Hugo Grocio y el mismo Locke incluyeron el derecho a castigar entre los derechos individuales de enforcement. ${ }^{6}$ La naturaleza de un derecho privado a castigar tiende a malentenderse fácilmente. Es necesario tener en cuenta que de la misma manera que el derecho a la defensa propia es un derecho que no autoriza a los individuos a hacer lo que quieran como medio de defenderse, el derecho a castigar tampoco implica que los individuos puedan usar cualquier procedimiento o aplicar cualquier tipo de castigo. ${ }^{7}$ Tanto en el caso de la defensa propia como en el caso de un derecho a castigar, pueden existir claras restricciones tanto en cuanto a las condiciones como en cuanto a las formas en las que uno puede actuar de acuerdo al permiso otorgado. Tanto en el caso del derecho a la defensa propia como en el caso de un derecho a castigar, el hecho de que individuos particulares puedan "abusar" de ese derecho no parecería una consideración suficiente para rechazar su validez e importancia, contrariamente a lo que a veces parece asumirse. $^{8}$

Contrariamente a lo que sucede con los otros derechos de enforcement, sin embargo, el derecho a castigar no fue entendido por Grocio o Locke como un derecho exclusivo de la víctima. Mientras que consideraron que los individuos pueden siempre elegir ejercitar el derecho a la defensa propia o a obtener restitución, Locke y Grocio argumentaron que

6 Véase Grocio (1625) y Locke (1690: Cap. 2, §§ 7-12).

$7 \quad$ Locke es explícito en este sentido: “And thus, in the state of nature, one man comes by a power over another; but yet no absolute or arbitrary power, to use a criminal, when he has got him in his hands, according to the passionate heats, or boundless extravagancy of his own will; but only to retribute to him, so far as calm reason and conscience dictate, what is proportionate to his transgression". Locke (1690: Chapter 2, § 8).

$8 \quad$ Véase, por ejemplo, Postema (1980). 
el derecho a castigar no es poseído por la víctima, tal que la víctima tienen un derecho que impide a otros a aplicar el castigo sin su consentimiento. Grocio sostuvo que el derecho a castigar es un derecho que recae en cada uno de los habitantes de un estado de naturaleza, y no meramente en la víctima, porque "an injury inflicted even upon one individual is the concern of all". ${ }^{9}$ De manera similar, Locke creía que dado que el criminal impone un peligro a toda la humanidad, cualquier individuo debería tener el derecho de castigarlo para así disuadir a ese criminal y a otros. ${ }^{10}$

La afirmación de que los individuos tienen un derecho natural a castigar en el sentido defendido por Grocio y Locke es quizás el aspecto más controvertido de la tradición del liberalismo lockeano. Incluso Nozick, quien puede tomarse como el representante contemporáneo más importante de esta tradición, encuentra la plausibilidad de esta tesis poco clara. Nozick parecería estar de acuerdo que el derecho a castigar no puede ser entendido como un derecho privado exclusivo, contrariamente a lo que sucede con el derecho a obtener restitución. En el caso de este derecho, Nozick dice, "the victim is the one to whom compensation is owed, not only in the sense that the money goes to him, but also in that the other is under an obligation to him to pay $\mathrm{it}^{\prime \prime},{ }^{11} \mathrm{y}$ por lo tanto, "the victim seems the appropriate party to determine precisely how it is to be enforced". ${ }^{12}$ Pero, de acuerdo a Nozick, las cosas son diferentes cuando hablamos del castigo. El castigo, dice Nozick, se le debe al agresor y no a la víctima. Por esta razón, Nozick sugiere que el derecho a castigar debería ser entendido como un derecho a participar en las decisiones relativas a las condiciones bajo las cuales se debe aplicar el castigo, y no como un derecho universal a castigar que cualquiera puede ejercer, tal como sugieren Grocio y Locke.

La sugerencia de Nozick, sin embargo, está lejos de ser del todo convincente. ¿Qué implica exactamente tener un derecho a participar en las condiciones bajo las cuales se debe aplicar el castigo? ¿Significa esto que la forma de castigar a un individuo que ha violado los derechos de otros se debe determinar por un voto mayoritario? ¿O significa que cada individuo tiene un derecho a vetar las propuestas punitivas de cualquier otro individuo? Si el derecho a castigar es un derecho a participar en este tipo de decisión, ¿significa que cualquier decisión a la que se llegue es moralmente legítima? Esta sugerencia

9 "Pertinet autem ad omnes quodammodo iniuria etiam uni illata [...]". Grotius (1604: 2, fol. 8).

10 "In transgressing the law of nature, the offender declares himself to live by another rule than that of reason and common equity, which is that measure God has set to the actions of men, for their mutual security; and so he becomes dangerous to mankind, the tye, which is to secure them from injury and violence, being slighted and broken by him. Which being a trespass against the whole species, and the peace and safety of it, provided for by the law of nature; every man upon this score, by the right he hath to preserve mankind in general, may restrain, or, where it is necessary, destroy things noxious to them, and so may bring such evil on any one, who hath transgressed that law, as may make him repent the doing of it, and thereby deter him, and by his example others, from doing the like mischief. And in this case, and upon this ground, every man hath a right to punish the offender, and be executioner of the law of nature" Locke (1690: Chapter 2, § 8). Locke también sostiene, "each transgression may be punished to that degree, and with so much severity, as will suffice to make it an ill bargain to the offender, give him cause to repent, and terrify others from doing the like" (1960: Cap. 2, § 12). Para un análisis de los elementos retribucionistas y utilitaristas en la teoría de Locke, véase Calvert (1993) y Tukness (2010).

$11 \quad$ Nozick (1974: 137)

12 Nozick (1974: 137). 
parecería ser extremadamente inverosímil. Pero si existe un criterio independiente de las decisiones a las que lleguen los individuos, ¿por qué es que el derecho a castigar se debe entender en estos términos deliberativistas? Como víctima, en un estado de naturaleza hipotético, ¿debe un individuo obtener el acuerdo de los demás para que el castigo que aplique al agresor sea moralmente legítimo?

De acuerdo a la perspectiva defendida en este artículo, deberíamos entender el derecho a castigar bajo las mismas líneas argumentales que entendemos los otros derechos de enforcement. La justificación del castigo no necesita basarse en una preocupación meritocrática impersonal, tal que ningún individuo particular podría arrogarse el derecho a ejercitarlo, tal como parecería sugerir Nozick. Tampoco necesita justificarse sobre la base de una preocupación relativa al orden social como un todo, tal que tampoco ningún individuo podría reclamar un derecho exclusivo a ejercitarlo, tal como parecen creer Grocio y el mismo Locke. El derecho a castigar podría justificarse sobre las mismas preocupaciones de seguridad individual que nos llevan a justiciar los otros derechos de enforcement. Esta justificación del castigo no sólo es más coherente con las premisas individualistas de la tradición lockeana. Es, en sí misma, una justificación más convincente de la práctica del castigo de la que proveen los tradicionales enfoques. Pues, contrariamente a los enfoques retribucionistas típicos, se brinda un reconocimiento moral a la instrumentalidad del castigo. Contrariamente a los enfoques consecuencialistas, no se asocia a esa instrumentalidad con un requerimiento siempre problemático de maximización impersonal.

Como sugiere Warren Quinn, las teorías tradicionales del castigo yerran en asumir que el derecho a amenazar a castigar deriva del derecho a castigar, cuya justificación debe proveerse de una forma independiente. El derecho a castigar deriva, por el contrario, del derecho individual a formular amenazas de retaliación.

Imaginemos, por ejemplo, que por alguna razón un individuo decide instalar una cerca de puntas afiladas de tal forma en que esas puntas están dirigidas hacia el interior de la propiedad y no hacia el exterior. Es decir, es sencillo traspasar la cerca sin causarse daño. El daño ocurre al intentar salir, es decir, después de que la ofensa se haya realizado. Parecería que no habría una razón convincente para negarles a los individuos el derecho a instalar ese tipo de cercas. Como pregunta el mismo Quinn, "What morally relevant difference could it make to a would-be wrongdoer that the injury whose prospect is designed to discourage him will come earlier or later?"13 Si es moralmente permisible instalar esas cercas, ¿no debería también ser permisible amenazar a los individuos con un daño que tendrá lugar una vez que realicen las ofensas?

Como ya habíamos notado, la formulación de amenazas de retaliación demanda menores recursos que la instalación de mecanismos de prevención físicos, como son las cercas electrificadas, y esta es una importante razón sobre la cual se asienta el reconocimiento de esta capacidad como un derecho. Pero ahora, de la misma manera que uno no es moralmente culpable del daño que las cercas de puntas para adentro causan al agresor 
cuando decide cometer su ofensa, los individuos no podrían ser moralmente culpables del daño real que sus actos de castigo causen al agresor una vez que haya cometido su ofensa. En ambos casos el individuo sabía lo que ocurriría si realizaba la acción que no tenía derecho a realizar. Si los individuos tienen derecho a construir lo que podríamos concebir como mecanismos de castigo "automáticos", es decir, mecanismos que infligen daño una vez que la ofensa tiene lugar, seguramente los individuos tendrían que tener derecho a infligir ese daño de una forma "manual" y no automática.

Quizás no estemos convencidos de que simplemente porque podríamos evitar la posibilidad de tener que castigar a un individuo mediante la construcción de mecanismos "automáticos" de castigo, no existe necesidad de proveer una justificación para castigar "manualmente", si es que de hecho no decidimos instalar el mecanismo "automático". ${ }^{14}$ Podemos imaginar que las circunstancias del caso han cambiado drásticamente, y que al momento de tener que decidir si infligir o no un castigo al agresor éste se arrepiente genuinamente de lo que ha hecho, y tenemos absoluta certeza de que no habrá ningún beneficio derivado del acto del castigo. Es debatible si es permisible castigarlo o no bajo estas circunstancias. Pero pocos creerán que la consideración que importa en ese debate es el mero hecho de que teníamos un derecho a amenazar con castigar previamente. Ese derecho a amenazar con castigar no está en discusión. Pero no parecería ser suficiente para contestar la pregunta que se nos plantea ahora. ¿Por qué no tendríamos que justificar esta acción, que ahora debemos decidir si realizarla o no, por la mera razón que pudiésemos haber instalado un mecanismo automático, que nos hubiese ahorrado esta decisión, pero que de hecho no hemos instalado?

Qué tan plausible consideremos esta particular línea de argumentación en la justificación de un derecho a castigar podría depender, en última instancia, de qué tan plausible pensamos que es la idea de que existen limitaciones al daño que es permitido imponer mediante esos mecanismos "automáticos" de disuasión. Si no existiesen esos límites, no es claro por qué existirían esos límites tampoco a la hora de aplicar un castigo. Pero esto choca contra ciertas convicciones morales arraigadas sobre la proporcionalidad del castigo. A primera vista, sin embargo, no es claro que existan esos límites. ¿Por qué no sería permisible amenazar a alguien con un daño inmenso para conseguir un efecto disuasivo si esa amenaza de daño no involucra a ninguna persona inocente y el efecto disuasorio no afecta ninguna de las acciones que otros tienen derecho a realizar?

Quinn parecería creer, sin embargo, que sí existen esos límites. Quinn sostiene que existen límites, similares a los que se aplican a la defensa propia, sobre las amenazas que uno puede legítimamente formular contra a otros. Quinn cree que sería "seriamente incorrecto" construir una cerca eléctrica muy peligrosa alrededor de una parcela vacía de tierra. ${ }^{15}$ Pero es difícil de entender por qué esto sería así, al menos en ciertos casos. ¿Sería moralmente incorrecto mantener a los ladrones alejados de nuestro reloj resistente al agua sumergiéndolo en un tanque plagado de tiburones? ${ }^{16}$ Evidentemente no. Pero 
si esto es cierto, y si pensamos que la justificación del castigo se deriva directamente del derecho a amenazar con castigar, ¿no tendríamos que concluir que no hay límites al castigo legítimo que es permisible imponer a otro? ¿No deberíamos concluir que es permisible arrojar al ladrón al tanque de tiburones si olvidamos poner el reloj en él y el ladrón tiene éxito en robarlo?

Independientemente de lo que uno pudiera pensar acerca del valor de esta particular línea de argumentación, este tipo de reflexiones sobre las relaciones que existen entre la capacidad de construir mecanismos disuasivos, el derecho a formular amenazas de retaliación y el derecho a castigar traen a nuestra atención algo de fundamental importancia. El derecho a formular amenazas de retaliación, que consideramos vital en permitir a los individuos economizar en recursos de protección, sería privado de gran parte de su valor si los individuos no estuvieran autorizados a llevar esas amenazas a la práctica. Como señala Daniel Farrell, "this would leave anyone who was willing to do only what she was morally justified in doing in an extremely vulnerable position, strategically, so far as deterring unjust aggression is concerned" ${ }^{17}$

Farrell piensa que cuando reflexionamos sobre el derecho de defensa propia, un principio plausible de justicia distributiva sostendrá lo siguiente: "When someone knowingly brings it about, through his own wrongful conduct, that someone else must choose either to harm him or to be harmed herself, justice allows the latter to choose that the former shall be harmed, rather than that she shall be harmed" ${ }^{18}$ Pero este principio extremadamente plausible en el caso de la defensa propia nos debería llevar a considerar un principio similar en el caso del castigo. ¿Por qué los individuos no estarían autorizados a hacer efectivas sus amenazas de retaliación contra aquellos que los hayan dañado, cuando no hacerlo incrementa su vulnerabilidad de ser el blanco de futuros ataques? ¿Por qué la víctima, en vez del agresor, sería quien tenga que sufrir este daño adicional cuando ha sido el agresor quien ha creado este estado de cosas?

Bajo esta particular forma de argumentación sugerida por Farrell no se sostiene que el castigo está justificado meramente porque estamos justificados en emitir amenazas de retaliación en el primer lugar, como pareciera sugerir Quinn. El argumento es que estamos justificados en castigar a aquellos que nos dañan porque ellos son los que nos han puesto en la situación de tener que enfrenar un incremento en nuestra vulnerabilidad frente a los otros, o hacer nuestras amenazas efectivas, y así restaurar nuestra credibilidad. Frente a esta elección, de nuevo es difícil de negar que sea el agresor, y no la víctima, el que debe afrontar el costo esperado que ha creado su acción de transgresión. Ciertamente, los críticos de un derecho natural a castigar no creen que si no existiese el Estado los individuos no tendrían derecho a amenazar a otros de tal forma de proveerse con seguridad para sus vidas y propiedad. Sin este derecho se verían obligados a asignar gran parte de sus recursos productivos para fines de prevención y seguridad. Pero si se concede esto, ¿es plausible sostener que si los otros ignoraran esas amenazas de 
retaliación las víctimas deberían abstenerse de hacerlas efectivas? Evidentemente, si ese fuera el caso, esas amenazas carecerían de todo valor, y volveríamos a esa situación en la que los individuos deben empobrecerse para asegurar su protección.

Como es el caso en las teorías retribucionistas del castigo, en este enfoque alternativo el sujeto del castigo se determina mirando hacia atrás, hacia la realización de la ofensa. Contrariamente a las teorías retribucionistas, sin embargo, el castigo tiene un claro rol de protección. Pero a diferencia de las teorías utilitaristas, la disuasión no se convierte en el único valor del castigo, y así no implica la legitimidad de castigar a inocentes. Uno puede castigar al real agresor y no a otros, porque él ha sido quien ha puesto a la víctima en esta situación de vulnerabilidad, que solamente la realización de la amenaza puede remediar.

Es interesante notar que, en cierto sentido, bajo esta perspectiva, el castigo podría ser concebido meramente como un aspecto del derecho a obtener restitución. Pues la posición original de la víctima no estaría totalmente restituida si no tenemos en cuenta el incremento en la vulnerabilidad que la víctima presenta si no fuese capaz de hacer efectivas sus amenazas de retaliación. El derecho a obtener restitución, por su parte, es uno de los derechos menos controvertidos. Incluso aquellos que rechazan la legitimidad moral del castigo no suelen rechazar la legitimidad moral de un derecho de restitución. Este es el caso, por ejemplo, de David Boonin.

\section{CULPABILIDAD, PROPORCIONALIDAD Y EXCUSABILIDAD}

En su reciente libro, David Boonin ha reconocido el carácter innovador y la promesa que ofrece este tipo de enfoque. ${ }^{19}$ Sin embargo, Boonin cree que existen varias objeciones decisivas en contra. Algunas de esas objeciones sólo son aplicables al particular enfoque de Warren Quinn, según el cual la misma pregunta sobre la justificación del castigo parecería diluirse en la justificación otorgada para los mecanismos de castigo "automáticos". Otras objeciones que Boonin analiza parecerían ser más generales, y son este tipo de objeciones las que me interesa tratar aquí.

La primera de esas objeciones tiene que ver con la posibilidad de castigar a personas inocentes. Boonin señala lo siguiente:

If the state threatens to do nothing at all in response to violations of the law, many innocent people will be harmed. If it threatens only to harm offenders, this will deter some people from breaking the law but not others. An if it threatens to harm offenders and their children, this will deter even more people from breaking the law. Suppose [...] that if the state chooses this third option, some people will still break the law, but for every one innocent child who will end up being harmed as a result, five other innocent people (maybe even innocent children) will be saved from being victimized by offenders in the first place. When faced with this choice, 
the distributive justice approach implies that the state is entitled to shift the harm as much as possible away from the innocent and towards the guilty. Threatening to harm offenders themselves will help accomplish this. But threatening to harm offenders and their children will accomplish even more. This solution will do the best job of shifting harm from the innocent to the guilty and so will be endorsed by the distributive justice approach. ${ }^{20}$

Esta primera objeción está basada en un claro malentendido, que es producto de concebir una concepción del castigo como una reflexión independiente de la teoría más amplia de los derechos individuales desde la cual se construye. Boonin parecería entender el tipo de enfoque que aquí presentamos como necesariamente formulado en términos consecuencialistas. Pero esto es evidentemente falso. Por el contrario, las premisas individualistas sobre las que se asienta este enfoque parecerían sugerir que su interpretación más natural es en términos deontológicos.

Para el consecuencialismo, la acción correcta es aquella que produce el estado del mundo mejor rankeado en términos de una determinada concepción del bien. La deontología, en cambio, es habitualmente entendida como un sistema de restricciones sobre la maximización de valor impersonal. Aunque siempre es posible entender los valores que los derechos individuales protegen como un valor a ser maximizado, esta no es la posición característica de la tradición lockeana. La posición característica entiende esos derechos como restricciones, o "side-constraints". Así entendidos, los derechos individuales impiden amenazar y castigar a personas inocentes incluso cuando esas amenazas y castigos puedan producir un mejor estado de cosas en términos del respeto a esos mismos derechos. Este es un aspecto de las posiciones deontológicas que se ha considerado paradójico, al menos desde un punto de vista teórico. ${ }^{21} \mathrm{Si}$ reconocemos el valor que protegen los derechos individuales, ¿no deberíamos estar dispuestos a violar los derechos de algunos individuos inocentes si eso nos permitía evitar que se violen los derechos de un grupo mayor? Si bien ofrecer una respuesta a esta pregunta es de fundamental importancia, es necesario resaltar que la crítica de Boonin tiene que ver con la posibilidad de castigar a inocentes, y este es un problema que surge precisamente cuando rechazamos la deontología en favor del consecuencialismo.

Desde una perspectiva lockeana, los derechos individuales imponen restricciones robustas a la maximización del bien impersonal. Como ya se señaló, la promoción de beneficios sociales o la promoción del bien prudencial o moral del mismo individuo no son consideradas desde esta perspectiva como consideraciones capaces, al menos en sí mismas, de justificar el desconocimiento de la voluntad individual. El derecho a amenazar no puede entonces ser ejercido contra ciertas personas inocentes de la forma que sugiere Boonin, incluso cuando efectivamente pueda ser la forma más efectiva de proteger a otras personas inocentes. 
La segunda objeción tiene que ver con el asunto de la proporcionalidad del castigo. Ya hemos visto la dificultad que, en este sentido, presenta la posición de Quinn. Quinn cree que si estamos moralmente autorizados a diseñar mecanismos de castigo "automáticos", estamos también autorizados a aplicar ese castigo de una forma "manual". Quinn sostiene que existen límites al daño que se pueden ejercer de una forma automática. Recordemos que Quinn sostiene que es moralmente incorrecto erigir una cerca electrificada muy peligrosa sobre una parcela vacía de tierra. Si no existe riesgo de dañar a personas inocentes, esta postura de Quinn es un tanto inverosímil si pensamos en el ejemplo del reloj de agua custodiado por tiburones. Sin embargo, si no existen límites al daño que se puede infligir de una forma "automática", ¿cuál es la razón por la cual existirían límites al castigo que estamos autorizados a infligir de una forma "manual"?

Boonin parece creer que esta es una implicancia más general del enfoque y no exclusiva de la teoría de Quinn. El problema surgiría porque, si el derecho a castigar deriva del derecho a amenazar con castigar, sólo tendríamos el derecho a aplicar el mismo castigo que tenemos derecho a amenazar. $Y$ en ciertos casos, este puede ser un castigo que es insuficientemente severo. Este el ejemplo provisto por Boonin:

Suppose that the threat of a $\$ 500$ fine would be enough to deter the vast majority of people from burning down someone's house. Suppose further that those who would not be deterred by this threat desire to commit arson so strongly that nothing short of a threat of death or torture would deter them. In this case, to protect our houses from being destroyed by arsonists, the self-defense solution would permit us to threaten them with a $\$ 500$ fine, but it would not permit us to threaten them with death or torture (and even if it did, that itself would be a problem). More importantly, it would not, for example, entitle us to threaten a greater fine or a fiveyear prison sentence, because we are only entitled to threaten to use the least force necessary to protect ourselves, and increasing the fine or adding a jail sentence would provide no further protection..$^{22}$

Boonin luego agrega, "the self-defense solution has no principled way of assuring proportional punishment". ${ }^{23}$

Es falso que una teoría del castigo del tipo que defendemos aquí no pueda otorgar una respuesta de principio y no meramente ad hoc al problema de la proporcionalidad. En primer lugar, es necesario notar que no es cierto que estemos obligados a admitir que si el derecho a castigar se deriva del derecho a amenazar con castigar sólo tendríamos el derecho a aplicar el mismo castigo que tenemos derecho con amenazar. Una vez que la transgresión ha tenido lugar, el castigo se justifica como una forma de restituir la situación estratégica de la víctima. Esta situación puede restituirse sin necesidad de llevar a la práctica el mismo grado de daño que la víctima estaba autorizada a amenazar. En principio, parecería que un castigo que se aproxime a aquel que es necesario y suficiente 
para disuadir a la mayor parte de los individuos cumpliría esa función de restitución. Así, si bien es cierto que ninguna respuesta exacta podría llegar a darse en este respecto, no es cierto que este tipo de enfoque se halle en una situación comparativamente inferior a los enfoques tradicionales.

Retornando a la posibilidad de que este enfoque justifique castigos que, en ciertos casos, son insuficientemente severos, pienso que es un aspecto interesante pero de escasa fuerza crítica. Siempre existirán individuos a los que es difícil de disuadir mediante las amenazas y castigos que la mayor parte de los individuos encuentran suficientes. Pero es ciertamente debatible, y está lejos de ser evidente, que esos individuos deben ser penados con castigos mayores cuando son aprehendidos. En el pasaje citado, Boonin mismo admite que sería problemático si la teoría justificase la muerte o la tortura, cuando él mismo ha estipulado que este tipo de castigo sería el único capaz de tener un efecto disuasorio. La objeción parecería limitarse entonces a la imposibilidad de incrementar la intensidad de un castigo que se reconoce sin efecto disuasorio. De nuevo, esta objeción carece en mi opinión de una fuerza crítica suficiente. La intuición moral con la que esa implicancia chocaría, si es que efectivamente dicha intuición existe, no forma parte de esas creencias morales arraigadas y reflexivas que toda teoría plausible debe respetar.

Una tercera objeción hacer referencia al problema de la excusabilidad. Boonin sostiene que el problema de este enfoque radica en lo siguiente:

[E]ither it treats provoked and unprovoked offenses the same way, and so must justify imposing the same punishment, or it treats them separately and so must justify imposing greater punishment for provoked offenses than for unprovoked offenses. In neither case, can the self-defense solution accommodate the belief that offenders who are provoked merit less punishment rather than more.

La razón por la cual Boonin cree que el enfoque justifica un castigo mayor para las ofensas provocadas es que se necesita una amenaza de daño mayor para disuadir las ofensas provocadas, debido a que las provocaciones tienden a causar un compartimiento menos prudente. De esta manera, de acuerdo a nuestra justificación del castigo, deberíamos estar autorizados a hacer efectiva esa amenaza de mayor daño.

Sin embargo, como ya se indicó, no es cierto que nuestro enfoque implica que tenemos el derecho a aplicar el mismo castigo que tenemos derecho con amenazar. El castigo se justifica como una forma de restituir la situación estratégica de la víctima, y es consistente con esta posición el sostener que en caso de provocación la víctima tiene parte de la responsabilidad, y así el castigo que se le imponga al agresor puede ser menor que aquel que corresponde a una situación en donde no hay provocación. De esta forma, no existe nada en el enfoque aquí propuesto que no permita acomodar, contrariamente a lo que sugiere Boonin, la creencia de que aquellos agresores que han sido provocados merecen un castigo inferior del que reciben aquellos que no lo han sido.

Finalmente, Boonin argumenta que este enfoque "would justify doing some acts that harm people who break the law, but it would not justify doing acts in order to harm 
them ${ }^{\prime 24}$. El problema que ve Boonin es que el castigo no involucra la mera aplicación de un daño, pero la aplicación de un daño intencional. No es del todo claro por qué Boonin cree que nuestro enfoque, aunque podría justificar el daño causado a los agresores, no podría justificar la intención de causarles daño. Es cierto que al formular una amenaza de retaliación la intención es meramente disuadir. Pero es difícil de comprender por qué el argumento no justificaría la intención de hacer efectiva dicha amenaza, cuando esa intención se entiende como la intención de aplicar un principio de justicia distributiva incontrovertible.

De todas maneras, esta objeción sobre la cual Boonin no sólo critica el enfoque que aquí defendemos, sino que también basa gran parte de la argumentación de su libro, es un tanto curiosa. Parecería confundir un asunto meramente terminológico, y como tal moralmente irrelevante, con una cuestión substantiva y de gran importancia práctica. Cuando buscamos una justificación del castigo, buscamos una justificación para un conjunto de acciones o prácticas sociales determinadas. Cuando preguntamos sobre la permisibilidad del castigo preguntamos, en definitiva, si deberíamos actuar o no de determinadas maneras. Poco realmente importa que, de acuerdo a la justificación dada de nuestras acciones, no estemos justificados en usar el término "castigo" para referir a ellas. Por supuesto, podríamos también cuestionar a Boonin que su definición de "castigo" es demasiado estrecha. Pero tendría que ser evidente la irrelevancia moral de esta discusión, y la intrascendencia que tiene para la justificación de una práctica social que no tenemos ningún problema en identificar.

\section{CONCLUSIÓN}

Juzgar la corrección de una justificación moral del castigo, o de cualquier otra práctica social, es un práctica esencialmente comparativa. El abolicionismo rechaza la moralidad del castigo, por ejemplo. La pregunta que debemos hacernos es si el argumento ofrecido por el abolicionismo es más convincente que el tipo de argumento ofrecido en este artículo. En mi opinión, la respuesta es claramente negativa. El argumento más básico del abolicionismo es de la idea de que infligir un daño a aquel que lo haya infligido en primer lugar equivale, meramente, a acrecentar el mal. Pero la plausibilidad del abolicionismo descansa en desconocer la naturaleza dinámica de la sociedad humana. Una vez que reconocemos este carácter dinámico, y adoptamos también una concepción realista de la misma naturaleza humana, comprendemos que la abolición del castigo implica un importante incentivo para la realización del mal.

Si el castigo es en realidad moralmente necesario en ese sentido, ¿cuál es entonces la mejor manera de articular una concepción de dicha moralidad? El enfoque retribucionista nos dice que el castigo es merecido por el criminal. No existe en este enfoque la posibilidad de castigar a inocentes. Pero el argumento principal que nos lleva a alejarnos del abolicionismo no encuentra un lugar preponderante en este enfoque. De acuerdo a la 
perspectiva retribucionista típica, el castigo se justifica independientemente de cuál sea su contribución en la producción de seguridad. El utilitarismo intenta remediar esta falencia colocando a la noción de disuasión como fundamento de su justificación. Pero en la particular formulación utilitarista, el valor fundamental que se le asigna a la disuasión implica la legitimidad de castigar a personas inocentes si fuese esto necesario para la mejor procuración de ese valor.

Reflexionar sobre los fundamentos morales del castigo en el contexto de una teoría más amplia de los derechos individuales nos permite articular de una manera más adecuada el valor que la disuasión debe poseer en una concepción plausible del castigo. Si reconocemos la importancia de una asignación de áreas estrictas de libertad moral o soberanía a todos los individuos, es natural también reconocer la importancia de aquellas acciones que pueden otorgar a los individuos de una garantía material sobre la seguridad de dichas áreas de libertad moral. Las amenazas de retaliación son fundamentales en este sentido debido a su bajo costo relativo. Ellas protegen los derechos de los individuos sin requerir una desviación previa de recursos de la forma en que sí la requiere la construcción o instalación de mecanismos de protección físicos. El efecto disuasorio que generan las amenazas de retaliación es virtualmente nulo, sin embargo, si carece de credibilidad. Si el castigo, es decir, la realización de dichas amenazas, no fuese permisible, los individuos que atendiesen a la moral se verían desprovistos de un importante mecanismo de protección, y no meramente de la posibilidad de infligir un daño, tal como los críticos del castigo habitualmente sostienen.

\section{REFERENCIAS}

Alexander, Larry. 1986. "Consent, Punishment, and Proportionality". Philosophy and Public Affairs 15 (2): $178-182$.

Calvert, Brian. 1993. "Locke on Punishment and the Death Penalty". Philosophy 68 (264): 211-229.

David Boonin. 2008. The Problem of Punishment, New York: Cambridge University Press.

Farrell, Daniel. 1985. "The Justification of General Deterrence". Philosophical Review 94 (3): 367-394.

Farrell, Daniel. 1988. "Punishment without the State". Nous 22: 437-453.

Farrell, Daniel. 1990. "The Justification of Deterrent Violence". Ethics 100: 301-317.

Grotius, Hugo. 1604. De iure praedae commentarius. A Collotype Reproduction of the Original Manuscript of 1604 in the Handwriting of Grotius belonging to the State University of Leyden, en J. B. Scott (ed.), The Classics of International Law 22, vol. 2, Oxford, Clarendon Press (1950).

Grotius, Hugo. 1635. On the Law of War and Peace, Traducción de A. C. Campbell, New York and London: M. Walter Dunne (1901).

Kagan, Shelly. 1989. The Limits of Morality. Oxford: Clarendon Press.

Kant, Immanuel. 1797. The Metaphysics of Morals, Cambridge: Cambridge University Press (1997).

Locke, John. 1690. Second Treatise of Government in Two Treatises of Government, Ed. Peter Laslett, Cambridge: Cambridge University Press (1960).

Mack, Eric. 2010. "The Natural Right of Property", Social Philosophy and Policy 27 (1): 53-78.

Nozick, Robert. 1974. Anarchy, State, and Utopia, New York: Basic Books.

Otsuka, Michael. 2003. Libertarianism without Inequality, Oxford: Clarendon Press, 2.

Postema, Gerald. 1980. “Nozick on Liberty, Compensation, and the Individual's Right to Punish". Social Theory and Practice 6 (3): 311-338.

Quinn, Warren. 1985. "The Right to Threaten and the Right to Punish". Philosophy and Public Affairs 14: 327-373. 
Rothbard, Murray. 1998. The Ethics of Liberty, New York: New York University.

Scheffler, Samuel. 1982. The Rejection of Consequentialism. Oxford: Clarendon Press.

Tuckness, Alex. 2010. "Retribution and Restitution in Locke's Theory of Punishment". The Journal of Politics 72: 720-732.

Vallentyne, Peter y Hillel Steiner (eds.). 2002. Left Libertarianism and Its Critics: The Contemporary Debate, New York: Palgrave Publishers Ltd.

Nicolás Maloberti, es Fellow del Liberty Fund, Indianápolis, y anteriormente se desempeñó como director de programas del Social Philosophy and Policy Center en Bowling Green, Ohio. Sus principales áreas de investigación incluyen la legitimidad política, los fundamentos filosóficos del liberalismo clásico, y el debate sobre la inmigración. 